\title{
The Study on Electrochemical Behaviors of the Interactions between Daunorubicin Hydrochloride and BSA
}

\author{
Jie Liu*, Bo Zhang \\ Taiyuan City Centre Hospital, Taiyuan, 030009 \\ *Corresponding authors. Email: tyzxyyyjk@163.com
}

\begin{abstract}
The Electrochemical behaviors of Daunorubicin hydrochloride, and the interactions between Daunorubicin hydrochloride and BSA were studied in this paper, with Linear sweep voltammetry and Cyclic voltammety methods. The results showed that, there was a reductive peak at $\mathrm{E}=-0.66 \mathrm{~V}$ in the Linear sweep voltammetry of Daunorubicin hydrochloride, on condition of $0.1 \mathrm{~mol} \cdot \mathrm{L}^{-1} \mathrm{Na}_{2} \mathrm{SO}_{4}, \mathrm{pH}$ 8.5B-R buffer solution. After BSA was introduced, the system peak current reduced. There was a maximal system peak current $\Delta \mathrm{ip}^{\prime \prime}$, when the concentration of Daunorubicin hydrochloride was $5.0 \times 10^{-5} \mathrm{~mol} \mathrm{~L}^{-1}$. At the range of $5.0 \times 10^{-8} \mathrm{~mol} \mathrm{~L}^{-1}-1.0 \times 10^{-4} \mathrm{~mol} \mathrm{~L}{ }^{-1}$ of the concentration of BSA, it existed a good linear relation between the reduced valve of the peak current of Daunorubicin hydrochloride and the concentration of BSA. This method can be used in the detection of the concentration of BSA.
\end{abstract}

Keywords: Daunorubicin hydrochloride; Bovine serum albumin; electrochemical behaviors; Linear sweep voltammetry; Cyclic voltammety

Citation: J. Liu, et al. The study on Electrochemical Behaviors of the Interactions between Daunorubic Hydrochloride and BSA. Nano Biomed. Eng. 2010, 2(2), 138-142. DOI: 10.5101/nbe.v2i2.p138-142.

\section{Introduction}

Daunorubicin (DNR) is one of the anthracycline anti-tumor agents widely used in the treatment of acute myeloid leukemia, mammary cancer, etc $[1,2]$. The molecular structure of daunorubicin has a anthracene nucleus plane [3] (Figure 1), can embed itself into the DNA base pair, then close combined with DNA, which can block DNA's spatial structure, thus inhibits the composition of nucleic acid [4,5]. It is shown that the aglucon of Daunorubicin can be embedded into the DNA base pairs, as the interaction between the positive charge on glycosyl group and negative charge on DNA phosphate group, the complexes on DNR and DNA is stable, so inhibits the DNA replication [6]. Also, Daunorubicin can act on DNA free radicals, causing the rupture of DNA chain and ultimately cell death. The study on the action mechanism of Daunorubicin can help to clarity the agent's storage and transport process in the body, which is an active research subject.

In recent years, people has studied the selective binding molecular mechanism on DNR and DNA base sequence, indicated that DNR could identify special DNA sequence as its best binding sites, then the best base sequence between DNR and DNA was forecasted [7]. To present, the analytical methods of DNR include HPLC, Capillary Electrophoresis, ESI mass spectrometry etc [8-10].

It is a marginal subject between chemistry and biology that the study on the interactions of the agent molecular and Bovine serum albumin (BSA) [11, 12]. from the point view of chemistry, it mainly includes binding sites, binding constant, force type, the effect of coexist substance, the distribution of drug in blood etc. BSA is a abundant carrier albumen in plasma, and can 
interact with many endogenous substances. In the elelments, which involved in many important life processes. So the study on the interactions of drugs and BSA has great significance.<smiles></smiles>

Figure 1. The molecular structure of daunorubicin

In this paper, electrochemical determination as a novel method for Daunorubicin hydrochloride was built. With Linear sweep voltammetry and Cyclic voltammety methods, the interactions between Daunorubicin hydrochloride and BSA were studied. This method is an ideal analysis method for drugs, which has the advantage in simpleness, speedness, high sensitivity.

\section{Materials and Methods}

\subsection{Materials and instruments}

LK 2005-type Electrochemical workstation (Lanlike chemical Electronics high-tech Co., Ltd., Tianjin). Three-electrode system: reference electrode-Saturated calomel electrode (SCE), supporting electrodeplatinum electrode, working electrode-Silver disk electrode $(\Phi: 50 \mu \mathrm{m})$. Type PHS-3C $\mathrm{pH}$ meter: (Ronghua Instrument Manufacturing Co., Ltd., Jintan). Type KQ-500B Ultrasonic cleaner (Ultrasonic Instrument Co., Ltd. Kunming). Daunorubicin hydrochloride standard stock solution $\left(1.0 \times 10^{-3} \mathrm{~mol} \cdot \mathrm{L}^{-}\right.$ $\left.{ }^{1}\right)$ : Accurately weighed $0.0564 \mathrm{~g}$ daunorubicin hydrochloride (mass fraction $>99.5 \%$ ), Dissolved in secondary distilled water and set the volume to $100 \mathrm{~mL}$ volumetric flask. Placed in brown reagent bottle, saved in cold and dark. Dilute to the desired concentration ready for use. Bovine serum albumin (BSA, Sigma Co., molecular weight: 68000) pH8.5 Britton-Robinson buffer solution, $0.1 \mathrm{~mol} \cdot \mathrm{L}^{-1} \mathrm{Na}_{2} \mathrm{SO}_{4}$ solution.

\subsection{Exprimental section}

(1) Electrode pretreatment: Use small metallographic sandpaper polish the silver disk electrode smoothly first, and use $\mathrm{Al}_{2} \mathrm{O}_{3}$ powder polished into a mirror on the thick cloth, then wash thoroughly with water and ethanol in sequence in the ultrasonic bath.

(2) The Electrochemical behaviors of Daunorubicin hydrochloride with Linear sweep voltammetry: In 10 biosome there are also many trace elements and macro $\mathrm{mL}$ comparison tube, mix $0.1 \mathrm{~mol} \cdot \mathrm{L}^{-1} \mathrm{pH} 8.5$ BrittonRobinson buffer solution $1 \mathrm{~mL}, 0.1 \mathrm{~mol} \cdot \mathrm{L}^{-1} \mathrm{Na}_{2} \mathrm{SO}_{4} 1$ $\mathrm{mL}$, corresponding Daunorubicin hydrochloride standard solution(or sample solution) in sequence, and diluted to the desired concentration using secondary distilled water. Then transfer to the electrolytic cell for linear sweep voltammetry scanning on electrochemical workstation. Set initial potential as $-0.4 \mathrm{~V}$, record the value of reductive peak current at-0.66 V, the concentration of Daunorubicin hydrochloride was calculated by calibration curve method.

(3) The interactions between Daunorubicin hydrochloride and BSA with Linear sweep voltammetry and Cyclic voltammety methods: In 10 $\mathrm{mL}$ comparison tube, mix $0.1 \mathrm{~mol} \cdot \mathrm{L}^{-1} \mathrm{pH} 8.5$ BrittonRobinson buffer solution $1 \mathrm{~mL}, 0.1 \mathrm{~mol} \cdot \mathrm{L}^{-1} \mathrm{Na}_{2} \mathrm{SO}_{4} 1$ $\mathrm{mL}, 1.0 \times 10^{-3} \mathrm{~mol} \cdot \mathrm{L}^{-1}$ Daunorubicin hydrochloride 0.5 $\mathrm{mL}$ and different concentrations of BSA in sequence, diluted to the desired scale. After fully mixed, stand for 10 minutes at ambient temperature, with solution without BSA as control.

\section{Results and discussion}

\subsection{Voltammetric response of daunorubicin} hydrochloride on Silver disk electrode

(1) Effects of supported electrolyte

$\mathrm{HC} 1, \mathrm{HAc}-\mathrm{NaAc}, \mathrm{KH}_{2} \mathrm{PO}_{4}-\mathrm{Na}_{2} \mathrm{HPO}_{4}$, BrittonRobinson buffer solution, $\mathrm{Na}_{2} \mathrm{SO}_{4}, \mathrm{KC} 1, \mathrm{NaCl}, \mathrm{NH}_{3}-$ $\mathrm{NH}_{4} \mathrm{Cl}$ and $\mathrm{NaOH}$, all of which were $0.1 \mathrm{~mol} \cdot \mathrm{L}^{-1}$, were selected respectively as supported electrolyte to study the impact on the peak current. The results showed that, Daunorubicin hydrochloride had a reductive peak in all of these mediums, while the best peak shape and largest peak current appeared in $\mathrm{Na}_{2} \mathrm{SO}_{4}$ solution, so $\mathrm{Na}_{2} \mathrm{SO}_{4}$ was selected as supported electrolyte.

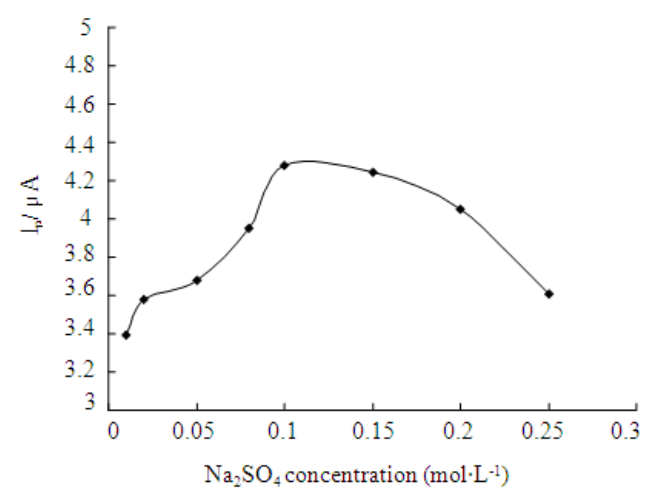

Figure 2. Election of $\mathrm{Na}_{2} \mathrm{SO}_{4}$ concentration

(2) Effects of base solution $\mathrm{pH}$

Use $\mathrm{Na}_{2} \mathrm{SO}_{4}$ as supported electrolyte, mesured at different concentrations with Linear sweep voltammetry method. As shown in Figure 2, the best peak shape and largest peak current appeared at the 
concentration of $0.1 \mathrm{~mol} \cdot \mathrm{L}^{-1}$. While less than $0.1 \mathrm{~mol}$. $\mathrm{L}^{-1}$, peak shape is poor; higher than $0.1 \mathrm{~mol} \cdot \mathrm{L}^{-1}$, the peak current decreased. So the concentration of $\mathrm{Na}_{2} \mathrm{SO}_{4}$ was selected $0.1 \mathrm{~mol} \cdot \mathrm{L}^{-1}$.

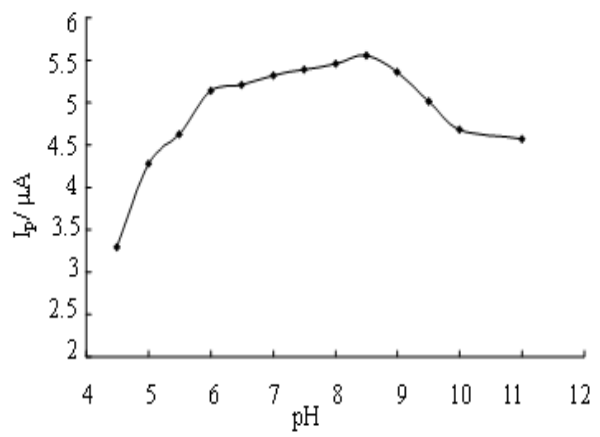

Figure 3. Effects between the $\mathrm{pH}$ and peak current

The peak current was measured by changing the $\mathrm{pH}$ value of solution with Britton-Robinson buffer solution, at the condition of $0.1 \mathrm{~mol} \cdot \mathrm{L}^{-1} \mathrm{Na}_{2} \mathrm{SO}_{4}$ as base solution, the concentration of Daunorubicin hydrochloride $5.0 \times 10^{-5} \mathrm{~mol} \cdot \mathrm{L}^{-1}$. The results showed that, the peak current reached maximum at $\mathrm{pH} 8.5$, and gradually became smaller with the increase of $\mathrm{pH}$ value. So the base solution acidity was selected pH8.5. (Figure 3).

(3) Linear sweep voltammograms of Daunorubicin hydrochloride on silver disk electrode.

According to the optimal condition, $0.1 \mathrm{molL}^{-1}$ $\mathrm{Na}_{2} \mathrm{SO}_{4}$ solution and pH8.5 Britton-Robinson buffer solution, different concentrations of Daunorubicin hydrochloride on silver disk electrode was analysed with Linear sweep voltammetry, potential scanning range from $-0.4 \mathrm{~V}$ to $-1.2 \mathrm{~V}$ (Figure 4 ). The results showed there was a reductive peak at $\mathrm{E}=-0.66 \mathrm{~V}$ in the Linear sweep voltammetry of the Daunorubicin hydrochloride, but no oxidation peak existed, which showed that the reaction was irreversible.

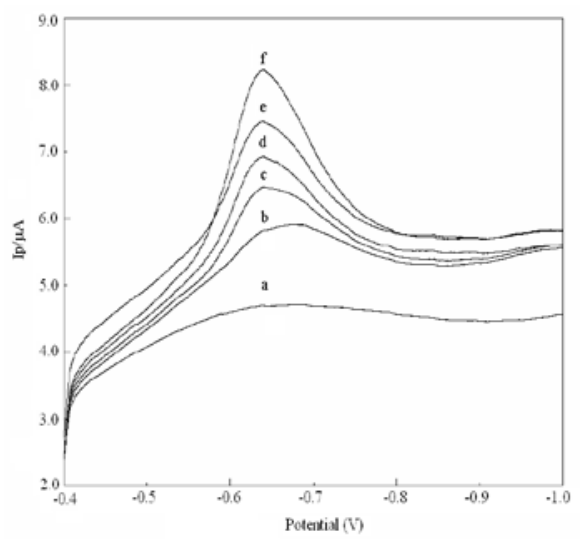

Figure 4. Linear sweep voltammetry curve of daunorubicin hydrochloride:a. 0 ; b. $1.0 \times 10^{-5} \mathrm{~mol} \cdot \mathrm{L}^{-1}$; c. $3.0 \times 10^{-5} \mathrm{~mol} \cdot \mathrm{L}^{-1}$; d. $5.0 \times 10^{-5} \mathrm{~mol} \cdot \mathrm{L}^{-1}$; e. $8.0 \times 10^{-5} \mathrm{~mol} \cdot \mathrm{L}^{-1}$; f. $1.0 \times 10^{-4} \mathrm{~mol} \cdot \mathrm{L}^{-1}$ (scanning rate: $100 \mathrm{mV} \cdot \mathrm{s}^{-1}$ )

\subsection{Electrochemical Behaviors of the interactions between Daunorubicin hydrochloride and BSA}

(1) Voltammetry of the interactions between Daunorubicin hydrochloride and BSA

In pH 8.5 Britton-Robinson buffer solution, there is a reductive peak $(\mathrm{Vp}=-0.63 \mathrm{~V})$ of Daunorubicin hydrochloride on silver disk electrode, The peak current (Ip) is proportional to the scanning speed (v), and the linear regression equation is $\mathrm{E}=-0.2086 \mathrm{v}$ $0.6463\left(\mathrm{Ep}: \mathrm{V}, \mathrm{v}: \mathrm{mV} \cdot \mathrm{s}^{-1}\right.$ ) with correlation coefficent $\mathrm{r}=0.998$, showed that daunorubicin hydrochloride in silver disk electrode reduction process is controlled by adsorption.

After BSA was introduced, no extra peak existed in scanning range, peak potential were essentially same,
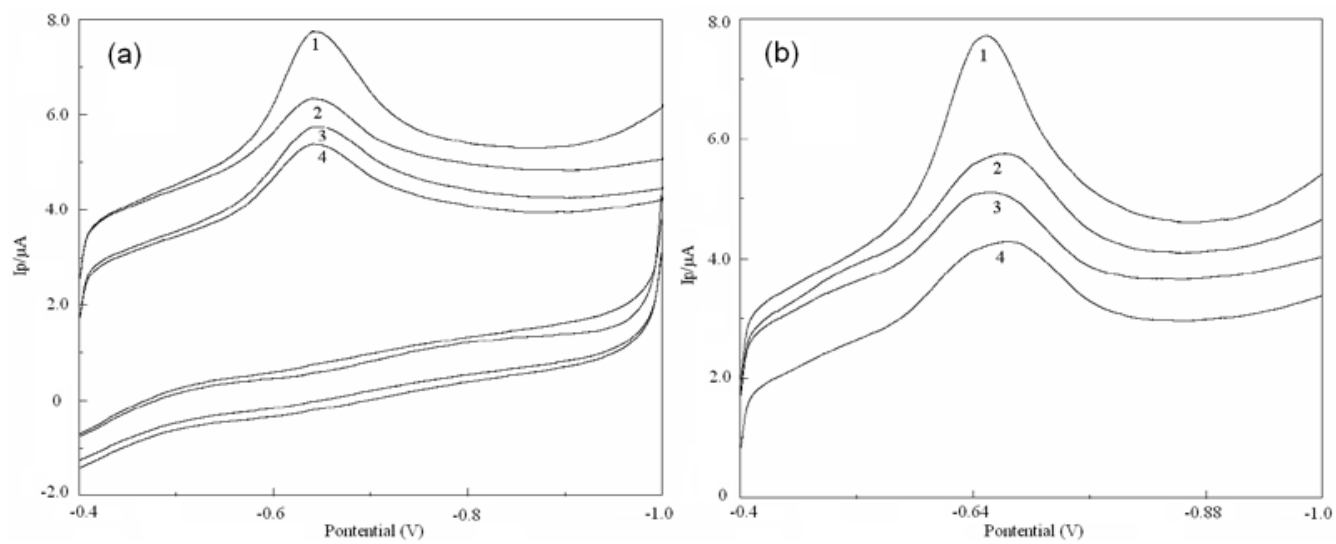

Figure 5. Cyclic voltammetry curve and Linear sweep voltammogram curve of reaction system of BSADaunorubicin hydrochloride. 1. $5.0 \times 10^{-5} \mathrm{~mol} \cdot \mathrm{L}^{-1}$ Daunorubicin hydrochloride; $2.1+\mathrm{BSA} 1.0 \times 10^{-5} \mathrm{~mol} \cdot \mathrm{L}^{-1} ; 3$. 1+BSA $1.5 \times 10^{-5} \mathrm{~mol} \cdot \mathrm{L}^{-1}$; 4. $1+\mathrm{BSA} 2.0 \times 10^{-5} \mathrm{~mol} \cdot \mathrm{L}^{-1}$. (a) Cyclic voltammetry curve (b) Linear sweep voltammogram curve. 
while reductive and oxidation peak current reduced. (Figure 5) The more BSA added, the greater the peak current reduced. It is indicated that the BSADaunorubicin hydrochloride complexes have no electrochemical activity. Since BSA-Daunorubicin hydrochloride complexes formed, the concentration of dissociative Daunorubicin hydrochloride decreased, hence the corresponding peak current reduced.

(2) Effects of Daunorubicin hydrochloride dosage on the reaction system

In $\mathrm{pH}$ 8.5 Britton-Robinson buffer solution, BSA concentration $1.0 \times 10^{-5} \mathrm{~mol} \cdot \mathrm{L}^{-1}$, the effects of Daunorubicin hydrochloride dosage were analysed with Cyclic voltammety method. The results showed that, the peak current $\Delta \mathrm{ip}^{\prime \prime}$ had a maximum when the concentration of Daunorubicin hydrochloride was $5.0 \times 10^{-5} \mathrm{~mol} \cdot \mathrm{L}^{-1}$. So $5.0 \times 10^{-5} \mathrm{~mol} \cdot \mathrm{L}^{-1}$ was selected as optimum concentration.

(3) The linear relation between the reduced valve of the peak current of Daunorubicin hydrochloride and the concentration of BSA.

Under optimum conditions, it existed a good linear relation between the reduced valve of the peak current of Daunorubicin hydrochloride and the concentration of BSA, at the range of $5.0 \times 10^{-8} \mathrm{~mol} \cdot \mathrm{L}^{-1}-1.0 \times 10^{-4}$ $\mathrm{mol} \cdot \mathrm{L}^{-1}$ of the concentration of BSA. The linear regression equation is Ip $(\mu \mathrm{A})=0.201 \mathrm{c}\left(\times 10^{-6} \mathrm{~mol} \cdot \mathrm{L}^{-1}\right)$ -0.0056 , with correlation coefficent $\mathrm{r}=0.997$ and minimum detectable concentration $5.0 \times 10^{-9} \mathrm{~mol} \cdot \mathrm{L}^{-1}$. 10 times comparative experiment were measured further, with relative standard deviation $1.64 \%$. It proves that this method can be used in the concentration detection of BSA.

\section{Conclusion}

(1) The Electrochemical behaviors of Daunorubicin hydrochloride were studied first, with Linear sweep voltammetry method. The results show that, there is a maximal reductive peak at $\mathrm{E}=-0.66 \mathrm{~V}$ in the Linear sweep voltammetry of the Daunorubicin hydrochloride, with the conditions of $0.1 \mathrm{~mol} \cdot \mathrm{L}^{-1} \mathrm{Na}_{2} \mathrm{SO}_{4}$, pH8.5B-R buffer solution. There is no oxidation peak existed, which showed that the electrode reaction was an irreversible process.

(2) The Electrochemical behaviors of the interactions between Daunorubicin hydrochloride and BSA, were studied then, with Linear sweep voltammetry and Cyclic voltammety methods. After BSA was introduced, the system peak current reduced, which indicated that the Daunorubicin hydrochlorideBSA complexes have no electrochemical activity. There was a maximal system peak current $\Delta \mathrm{ip}$ ", when the concentration of Daunorubicin hydrochloride was $5.0 \times 10^{-5} \mathrm{~mol} \cdot \mathrm{L}^{-1}$. At the range of $5.0 \times 10^{-8} \mathrm{~mol} \cdot \mathrm{L}^{-1}$ $1.0 \times 10^{-4} \mathrm{~mol} \cdot \mathrm{L}^{-1}$ of the concentration of BSA, it existed a good linear relation between the reduced valve of the peak current of Daunorubicin hydrochloride and the concentration of BSA. This method can be used in the detection of the concentration of BSA.

\section{Acknowledgements}

We thank Professor Yong Zhang for providing expert help with electrochemical observations. This work was supported by Taiyuan City Centre Hospital’s funding.

\section{References}

1. Mayako S, Fadia AK, Kenichi W. Effects of angiotensin II receptor blocker (candesartan) in daunorubicin-induced cardiomyopathic rats. Inter. J. Cardiol. 2006; 110: 378385 doi:10.1016/j.ijcard. 2005.08.061

2. Christina L, Linn H, Malin B. Mechanisms of crossresistance between nucleoside analogues and vincristine or daunorubicin in leukemic cells. Biochem. Biophys. Res.Commun. 2004; 320: 825-832 doi:10.1016/j.bbrc.20 $\underline{04.06 .016}$

3. Murphy G, Lawrence W J, and Lenhard R. American Society Textbook of clinical oncology. 2nd Edn., Atlanta: American Cance Society. 1995

4. Erdem A, Ozsoz M. Interaction of the anticancer drug epirubicin with DNA. Analytica Chimica Acta 2001; 437: 107-114 doi:10.1016/S0003-2670(01)00942-4

5. Cheng GF, Zhang DM, Ding M, et al. Studies on the interaction of Daunomycin and the specific sequence of DNA. Chem. J. Chin. U. 2003; 24: 1395-1399

6. Madeleine H M, William N J, Beatrice L d'E, et al. DNAdrug interactions: The crystal structure of d(CGATCG) complexed with daunomycin. J. Mol. Biol. 1989; 206: 693-705 doi:10.1016/0022-2836(89)90577-9

7. Haj H T, Salerno M, Priebe W, et al. New findings in the study on the intercalation of bisdaunorubicin and its monomeric analogues with naked and nucleus DNA Chem-Biol. Interact. 2003; 145: 349-358 doi:10.1016 /S0009-2797(03)00061-9

8. Lukawska M, Oszczapowicz I, Jelinska A, et al. Development and Validation of RP-HPLC Method for Determination of Novel Derivatives of Daunorubicin. Chem. Anal. 2009; 54: 907-917

9. $\mathrm{Lu} \mathrm{H}$, Yuan G, He Q, et al. Rapid analysis of anthracycline antibiotics doxorubicin and daunorubicin by microchip capillary electrophoresis. Microchem. J. 2009; 92: 170-173 doi:10.1016/j.microc.2009.03.005

10. Celine K, Vanessa T, Juan D R, et al. Mass spectrometric investigation of the DNA-binding properties of an anthracycline with two trisaccharide chains. Arch. Biochem. Biophys. 2008; 477: 348-355 doi:10.1016/j.abb. 2008.05.009

11. Erland JF, Ellen F. Kinetics of anthracycline accumulation in multidrug-resistant tumor cells: relationship to drug lipophilicity and serum albumin binding. Biochem. Pharmacol. 1998; 56: 1209-1217 doi:10.1016/S0 006 . 2952(98)00255-X

12. Ni Y, Sua S, and Serge K. Spectrofluorimetric studies on the binding of salicylic acid to bovine serum albumin using warfarin and ibuprofen as site markers with the aid of parallel factor analysis. Anal. Chim. Acta. 2006; 580: 206-215 doi:10.1016/j.aca.2006.07.059

Received 10 June, 2010; accepted 6 July, 2010; published online 9 July, 2010.

Copyright: (c) $2010 \mathrm{~J}$. Liu et al. This is an open-access article distributed under the terms of the Creative 
Commons Attribution License, which permits unrestricted use, distribution, and reproduction in any medium, provided the original author and source are credited. 